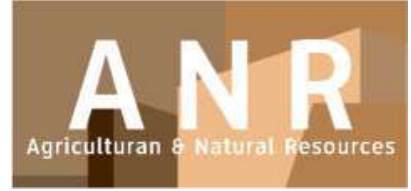

PAPER - OPEN ACCESS

\title{
Manfaat Ekonomi Damar Bagi Masyarakat di Sekitar Kesatuan Pengelolaan Hutan Lindung (KPHL) Larona Malili
}

\author{
Author $\quad$ : Rini Purwanti dan Nur Hayati \\ DOI $\quad: 10.32734 /$ anr.v2i1.574 \\ Electronic ISSN : :2654-7023 \\ Print ISSN : :2654-7015
}

Volume 2 Issue 1 - 2019 TALENTA Conference Series: Agricultural and Natural Resources (ANR)

\section{(2) $(1) \Theta$}

This work is licensed under a Creative Commons Attribution-NoDerivatives 4.0 International License.

Published under licence by TALENTA Publisher, Universitas Sumatera Utara

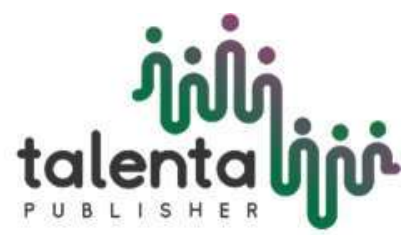




\title{
Manfaat Ekonomi Damar Bagi Masyarakat di Sekitar Kesatuan Pengelolaan Hutan Lindung (KPHL) Larona Malili
}

\author{
(Economic Benefits of Damar for Communities Around the Larona Malili Protection \\ Forest Management Unit) \\ Rini Purwanti $1^{*}$ dan Nur Hayati ${ }^{1}$ \\ ${ }^{1}$ Balai Penelitian dan Pengembangan Lingkungan Hidup dan Kehutanan, Makassar \\ Jl. Perintis Kemerdekaan Km. 16,5 Makassar, 90243, telp. (0411) 554049 \\ Email: rnpurwanti_up@yahoo.co.id
}

\begin{abstract}
Abstrak
Hutan lindung memberikan kontribusi yang besar terhadap ekonomi suatu wilayah terutama bagi masyarakat di sekitar hutan. Kontribusi ekonomi berasal dari pemanfaatan hutan lindung berupa produk dan jasa lingkungan yang mempunyai nilai ekonomi jangka panjang, baik yang bersifat langsung maupun tidak langsung. Pohon damar adalah jenis tanaman hutan yang tumbuh secara alami pada daerah Kesatuan Pengelolaan Hutan Lindung (KPHL) Larona Malili dan penyadapan getah damar merupakan salah satu kegiatan yang dapat dilakukan pada wilayah ini. Penelitian ini bertujuan untuk mengetahui potensi dan manfaat ekonomi damar bagi masyarakat di sekitar KPHL Larona Malili. Metode pengambilan data melalui observasi dan wawancara dengan 30 orang responden. Data dianalisis secara deskriptif kuantitatif. Data potensi damar dan pendapatan masyarakat dari pejualan getah damar di sekitar KPHL Larona Malili, diperoleh secara purposive sampling terhadap masyarakat yang memanfaatkan getah damar sebagai sumber pendapatan. Berdasarkan hasil penelitian diperoleh rata-rata potensi pohon damar responden adalah 50 pohon/ha dengan rata-rata produksi getah/pohon adalah $2.685 \mathrm{~kg} / \mathrm{tahun}$. Jika harga jual getah damar saat dilakukan penelitian sebesar Rp. 10.000/kg, maka pendapatan rata-rata responden dari nilai jual getah damar adalah sebesar Rp. 26.850.000/tahun. Hal ini menunjukkan, adanya pemanfaatan getah damar dapat meningkatkan kesejahteraan masyarakat di sekitar kawasan di KPHL Larona Malili.
\end{abstract}

Kata Kunci : manfaat ekonomi, getah damar, KPHL Larona Malili

\begin{abstract}
Abstrak
Protected forests make a large contribution to the economy of a region, especially for communities around the forest. The economic contribution comes from the use of protected forests in the form of the benefits of environmental products and services that have long-term potential value, both tangible and intangible. Damar trees are one of the types of forest plants that grow naturally in the Protected Forest Management Unit (PFMU) region Larona Malili and tapping dammar gum is one of the activities that can be done in this region. This study aims to determine the potential and economic benefits of resin for people around PFMU Larona Malili. Data collection methods through observation and interviews with 30 respondents. Data were analyzed descriptively quantitatively. Data on potential resin and community income from selling dammar gum around PFMU Larona Malili, obtained by purposive sampling for people who use dammar gum as a source of income. The results showed that the average potential of dammar trees owned by respondents was 50 trees / ha with an average production of sap / tree was $2.685 \mathrm{~kg} /$ year. If the selling price of resin is done when the research is $R p .10,000 / \mathrm{kg}$ then the average income of respondents from the selling value of dammar gum is Rp. 26,850,000 / year. This shows, the use of dammar gum can improve the welfare of people around the area in PFMU Larona Malili.
\end{abstract}

Keywords: economic benefits, dammar gum, PFMU Larona Malili

(C) 2019 The Authors. Published by TALENTA Publisher Universitas Sumatera Utara

Selection and peer-review under responsibility of Pertemuan Ilmiah Tahunan (PIT) dan Seminar Nasional Ke-4,

Komunitas Manajemen Hutan Indonesia (KOMHINDO)

p-ISSN: 2654-7015, e-ISSN: 2654-7023, DOI: 10.32734/anr.v2i1.574 


\section{Pendahuluan}

Hutan lindung merupakan kawasan hutan yang mempunyai fungsi utama sebagai perlindungan fungsi-fungsi ekologis hutan terutama menyangkut tata air dan kesuburan tanah. Hutan lindung selama ini dikeramatkan dan masyarakat lebih banyak mendapat informasi tentang larangan, dan belum banyak upaya konservasi yang partisipatif dengan memberikan hak kelola hutan kepada masyarakat untuk mengakses hutan secara bertanggung jawab. Upaya ini sangat penting karena dapat menimbulkan rasa peduli kepada masyarakat yang tinggal disekitar hutan, karena mereka merasa memperoleh manfaat secara langsung dengan keberadaan hutan tersebut. Ketika masyarakat merasa tidak mendapatkan manfaat dari hutan, maka masyarakat akan membiarkan terjadinya perusakan hutan. Konservasi yang bersifat partisipatif dapat dilakukan dengan mengijinkan masyarakat sekitar untuk mengakses manfaat hutan lindung secara bertanggung jawab. Hal ini sesuai dengan UU. No. 41 Tahun 1999 dan PP. No. 6 tahun 2007 serta ketentuan lain yang berlaku [1]. Bentuk-bentuk pemanfaatan hutan lindung yaitu berupa pemanfaatan kawasan, pemanfaatan jasa lingkungan, dan penyadapan HHBK (hasil hutan bukan kayu) [2].

KPHL Larona Malili terletak di Kabupaten Luwu Timur Provinsi Sulawesi Selatan, dan tersebar di lima wilayah kecamatan dalam lingkup wilayah Kabupaten Luwu Timur, didominasi oleh hutan lindung seluas 168.045,6 ha atau $48,76 \%$ dari luas total KPH merupakan kawasan hutan lindung. KPH ini juga memiliki hutan produksi yang relatif cukup luas, yaitu 85.173,2 ha yang terdiri atas kawasan hutan produksi terbatas seluas 78.782,1 ha dan hutan produksi biasa seluas 6.391,1 ha. Mengingat bahwa luas hutan lindung yang dominan, maka KPH di Kabupaten Luwu Timur ini dinamakan Kesatuan Pengelolaan Hutan Lindung (KPHL) [3].

Penyadapan hasil hutan bukan kayu (HHBK) merupakan salah satu kegiatan yang dapat dilakukan pada hutan lindung, dalam jangka panjang terbukti mempunyai nilai yang lebih besar dari pada kayu [4]-[5]-[6]. HHBK memberikan kontribusi pendapatan yang besar terhadap pendapatan total keluarga per tahun, dan dapat menjadi sumber penghasilan tambahan manakala sumber pendapatan lainnya gagal [7]-[8].

Damar (Agathis) merupakan jenis tumbuhan yang termasuk dalam famili Araucariaceae merupakan salah satu jenis tanaman hutan yang tumbuh secara alami pada wilayah KPHL Larona Malili. Tanaman ini memiliki batang yang silindris dapat mencapai tinggi $60 \mathrm{~m}$. Kulit luar batang mengelupas dalam keping-keping kecil. Kayu tanaman damar dapat dimanfaatkan sebagai kayu pertukangan, namun akhir-akhir ini pemanfaatannya dibatasi mengingat jumlah tanaman ini yang tumbuh pada hutan alam semakin berkurang. Selain itu tanaman tersebut menghasilkan resin yang diolah menjadi kopal. Resin ini adalah getah yang keluar pada saat kulit atau kayu damar dilukai. Getah akan mengalir keluar dan membeku setelah kena udara. Beberapa waktu getah tersebut akan mengeras dan dapat dipanen, yang dikenal sebagai kopal sadapan [3].

Pohon damar banyak terdapat di dalam kawasan hutan, baik hutan produksi maupun hutan lindung dan tersebar di 5 (lima) Kecamatan yaitu Kecamatan Towuti, Malili, Nuha, Wasuponda dan Angkona. Nama damar sendiri diambil karena pohon ini memproduksi kopal (getah) atau yang biasa kita sebut dengan "damar". Getah tersebut biasa digunakan untuk cat, vernis spiritus, plastik, bahan sizing, pelapis tekstil, bahan water proofing, tinta cetak, dan lain sebagainya.

Kegiatan pemanenan getah kopal (masyarakat menyebut kopal dengan nama damar) telah lama dilakukan oleh masyarakat yang berada di sekitar KPHL Larona Malili. Bahkan beberapa masyarakat telah menjadikan kegiatan pemanenan getah damar ini sebagai mata pencaharian pokok dan tenaga kerjanya semua berasal dari anggota keluarga. Oleh sebab itu tujuan penelitian ini adalah untuk mengetahui manfaat ekonomi damar bagi masyarakat di sekitar Kesatuan Pengelolaan Hutan Lindung (KPHL) Larona Malili.

\section{Metode Penelitian}

\subsection{Waktu dan Lokasi Penelitian}

Penelitian ini dilaksanakan selama 2 (dua) bulan dari bulan Februari sampai dengan April 2014, di KPHL Larona Malili, Kabupaten Luwu Timur, Provinsi Sulawesi Selatan. KPHL Larona Malili ditetapkan berdasarkan Keputusan Menteri Kehutanan Nomor : SK. 722/Menhut-II/2011 tanggal 20 Desember 2011. Berdasarkan letak geografis, wilayah KPHL Kab. Luwu Timur (Model Unit I Larona - Malili) terletak pada 120052' 25.7" sampai dengan $121^{0} 47^{\prime}$ 26.5” BT dan $2^{0} 22^{\prime}$ 56.3" sampai dengan $3^{\circ} 0^{\prime}$, 46.8” LS. Secara administratif wilayah pemerintahan, KPHL tersebut terletak di Kabupaten Luwu Timur Provinsi Sulawesi Selatan, dan tersebar di lima 
wilayah kecamatan dalam lingkup wilayah Kabupaten Luwu Timur yaitu kecamatan Angkona, Malili, Wasuponda, Towuti dan Nuha.

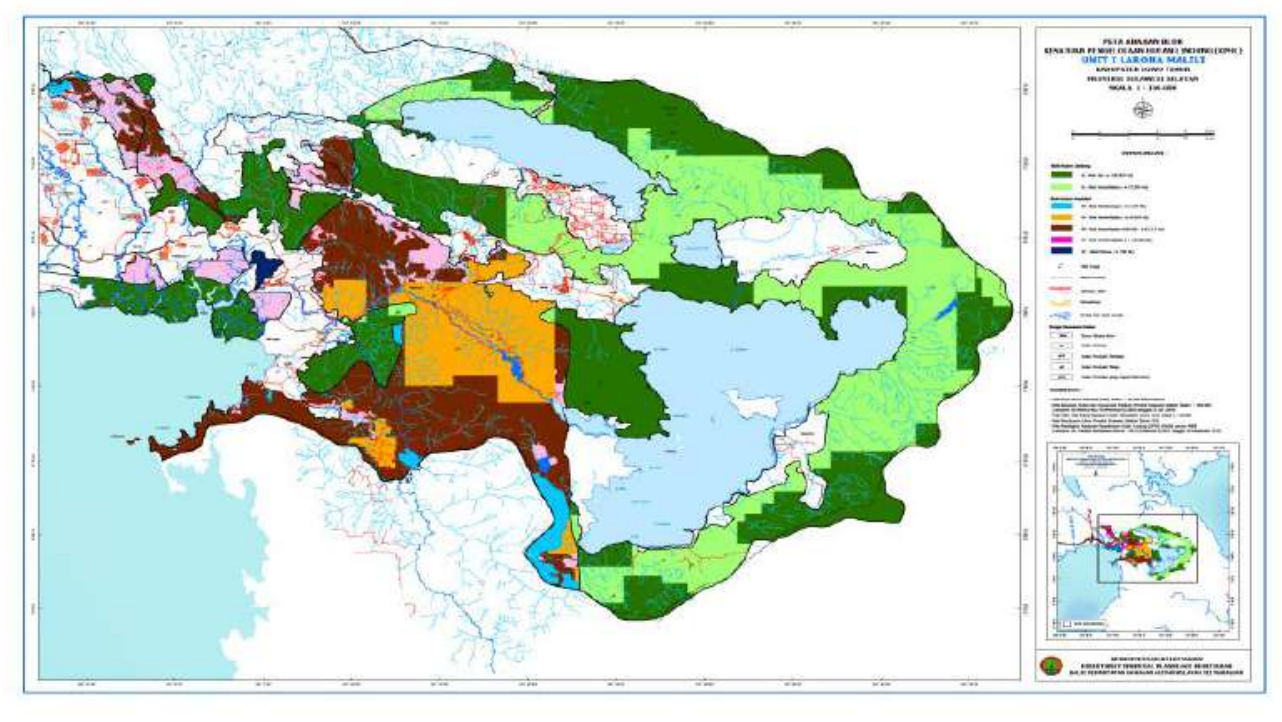

Gambar 1. Peta KPHL Larona Malili

\subsection{Pengumpulan Data}

Penelitian ini dilakukan untuk memperoleh data dan informasi tentang nilai manfaat ekonomi getah damar sebagai core business KPHL. Data yang dikumpulkan dalam penelitian ini didapat dari data primer dan data sekunder. Data primer yang dikumpulkan dalam kegiatan penelitian ini adalah nilai manfaat ekonomi getah damar, yang dalam hal ini adalah manfaat langsung damar (Direct Use Value : DUV). Sedangkan data sekunder yang yang akan dikumpulkan adalah data kondisi biofisik KPHL Larona Malili, potensi getah damar, serta harga jual damar. Untuk mengetahui nilai manfaat langsung getah damar dilakukan wawancara dengan responden penyadap getah damar.

Populasi responden adalah petani getah damar yang telah terdaftar pada Dinas Kehutanan Kabupaten Luwu Timur yang berjumlah 79 orang. Menurut [9], apabila jumlah populasi kurang dari 100, maka sebaiknya dilakukan sensus terhadap populasi tersebut. Namun menurut [10], jika tingkat homogenitas populasinya tinggi atau bahkan sempurna, maka ukuran sampel yang diambil boleh kecil. Sampel responden yang diambil dalam penelitian ini berjumlah 30 orang, hal ini karena tingkat jawaban yang diberikan responden hampir seragam terutama tentang produksi pohon damar per pohon sehingga dengan jumlah sampel yang sedikit ini diharapkan mewakili populasi yang ada.

\subsection{Analisa Data}

Data yang terkumpul dianalisis menggunakan analisis deskriptif dan kuantitatif melalui tabulasi data sederhana. Untuk mengetahui nilai ekonomi manfaat getah damar digunakan formulasi sebagai berikut :Nilai manfaat ekonomi getah damar $=$ Produksi getah damar $(\mathrm{kg} / \mathrm{ha}) \times$ Harga Jual $(\mathrm{Rp} / \mathrm{kg})$. 


\section{Hasil dan Pembahasan}

\subsection{Karakteristik Responden}

Umur responden: jumlah petani responden adalah 30 orang dengan rata-rata umur responden adalah 40 tahun. Umur terendah adalah 27 tahun dan maksimal adalah 84 tahun. Rata-rata responden penyadap getah damar tersebut masih berada diusia produktif (97\%) dan yang tidak produktif sebanyak 3\%. Menurut BPS, usia produktif yaitu antara umur 15-64 tahun.

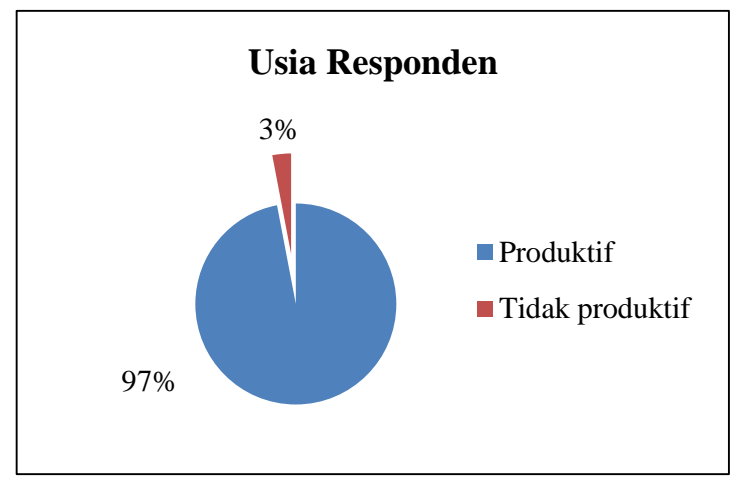

Gambar 2. Persentase usia responden

Pendidikan: pendidikan termasuk hal yang penting dan akan berpengaruh terhadap kesejahteraan penduduk. Di lokasi penelitian, pendidikan terendah responden adalah SD dan tertinggi adalah SMA, dan semua responden sudah bebas dari buta aksara. Berdasarkan keseluruhan responden, distribusi pendidikan terbanyak adalah SD (63\%), yang diikuti oleh SLTP (17\%) dan SLTA (20\%). Tingkat pendidikan dilokasi penelitian ini cenderung rendah, hal ini mengindikasikan bahwa pada umumnya mata pencaharian penyadap getah damar ini membutuhkan tenaga dan kekuatan yang ekstra karena harus melalui medan yang susah dan terjal sehingga ada kemungkinan yang memiliki pendidikan yang lebih tinggi tidak mau menjadi penyadap getah damar ini, dan lebih memilih bekerja dibidang yang lain.

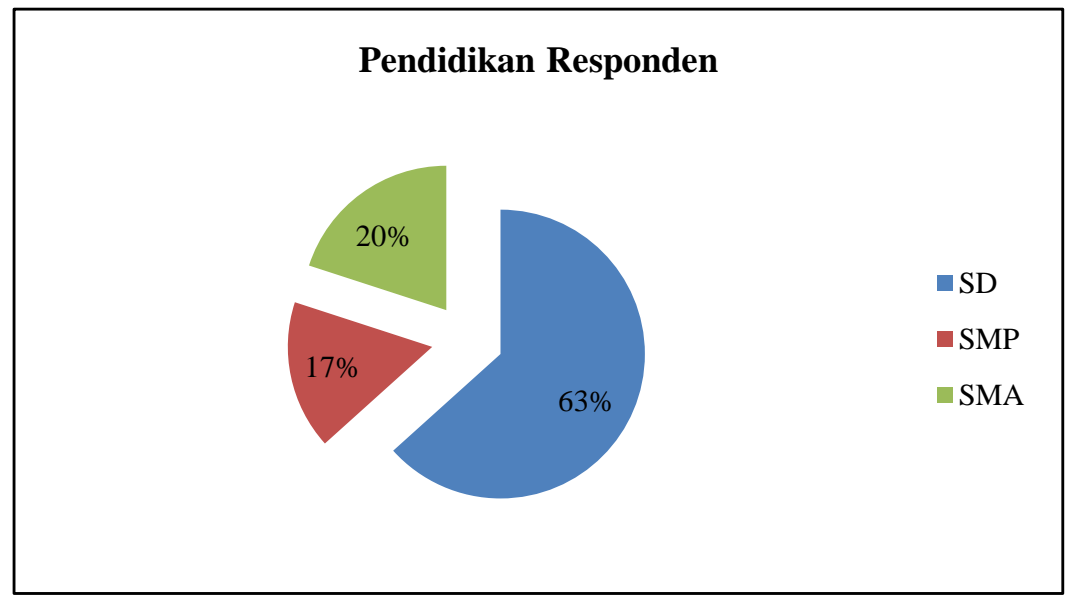

Gambar 3. Persentase pendidikan responden

Jumlah tanggungan: jumlah tanggungan keluarga responden bervariasi sampai yang tertinggi adalah 8 jiwa. Hal ini menunjukan semakin banyak jumlah tanggungan keluarga maka semakin banyak tanggungan pemikiran dalam menyelesaikan masalah termasuk keputusan untuk merubah kegiatan dalam usahanya. Sebaliknya semakin kecil tanggungan keluarga semakin rendah pengeluaran atau biaya sehingga makin banyak modal yang dapat dialokasikan dalam upaya peningkatan usahanya. 


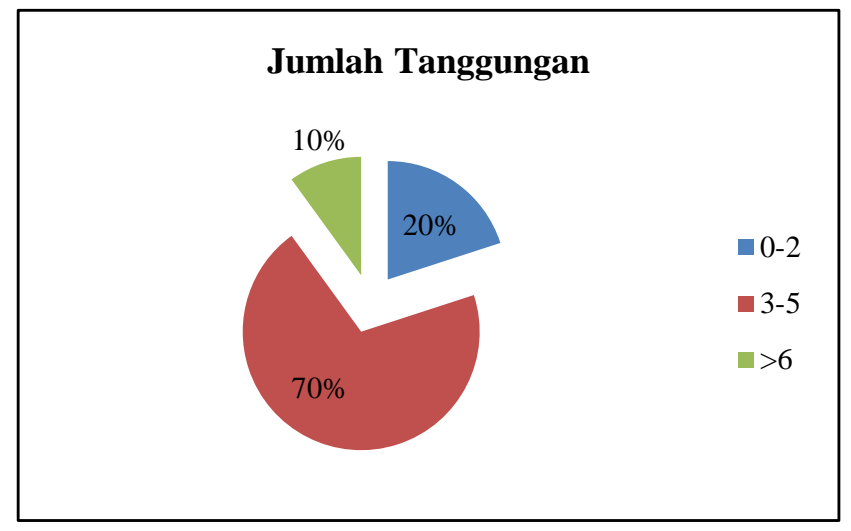

Gambar 4. Persentase jumlah tanggungan responden

Luas Lahan: kepemilikan lahan petani dan jumlah pohon damar erat hubungannya dengan pendapatannya. Dalam penelitian ini, luas lahan yang dimaksud adalah luas lahan milik pemerintah yang dikelola oleh masyarakat secara turun temurun. Lahan tersebut telah dikelola oleh orang tua mereka sejak jaman dahulu, dah bahkan ada pohon damar yang juga diwariskan oleh orang tua mereka hingga sekarang. Luas lahan yang dikelola bervariasi antara 3 ha -7 ha.

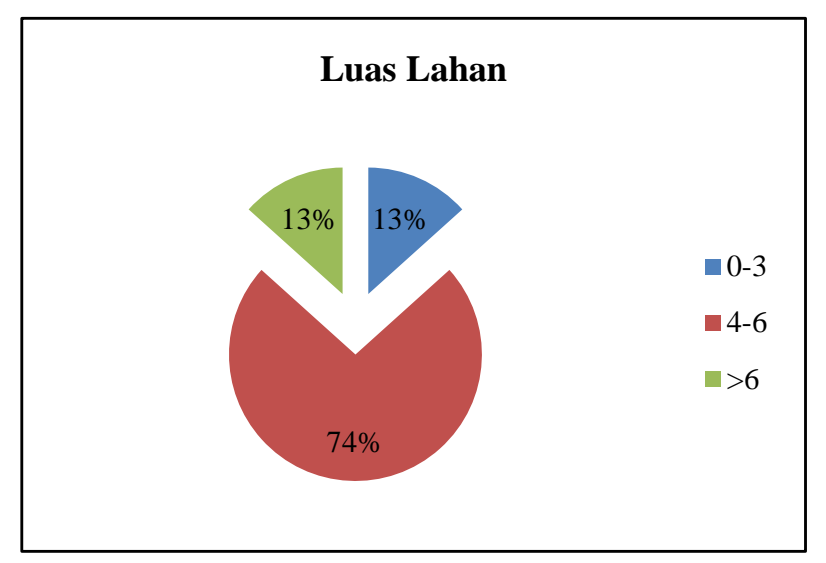

Gambar 5. Persentase luas lahan responden

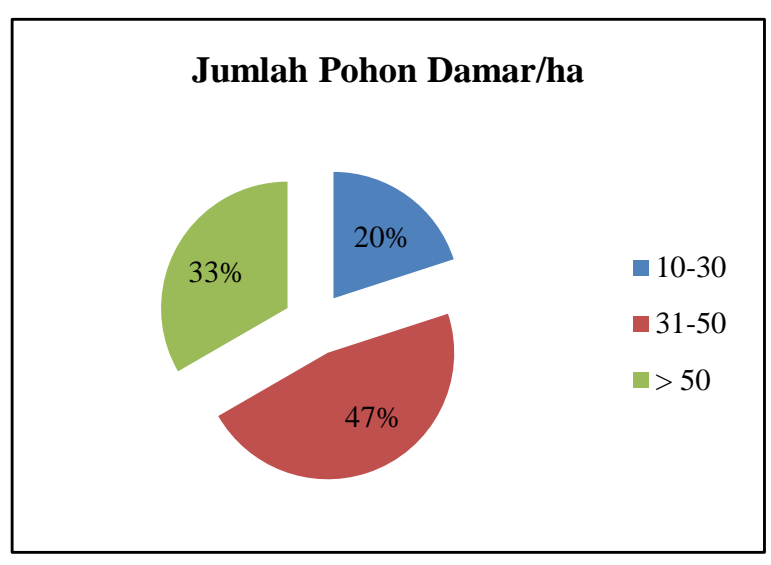

Gambar 6. Persentase jumlah pohon damar/ha

Jumlah pohon damar: jumlah pohon damar yang dimiliki oleh responden juga sangat bervariasi, mulai dari jumlah pohon terendah yaitu 14 pohon/ha hingga yang tertinggi yaitu 100 pohon/ha dengan rata-rata jumlah pohon adalah 50 pohon/ha (Gambar 6). Sementara jumlah produksi per pohon tidak terlalu jauh bedanya, produksi terendah $2 \mathrm{~kg} /$ pohon $/ 3$ bulan dan produksi tertinggi $5 \mathrm{~kg} /$ pohon $/ 3$ bulan dengan rata-rata produksi adalah 3 $\mathrm{kg} /$ pohon$/ 3$ bulan. Kegiatan penyadapan getah damar ini pada umumnya dilakukan setiap 3 bulan sekali, karena menurut responden jika getah dibawah umur 3 bulan masih basah sehingga nantinya akan menyulitkan pada saat pemanenan dan penyimpanannya di dalam karung (lengket satu sama lain).

\subsection{Pemanenan Getah Damar (Agathis dammara)}

Kegiatan pemanenan getah kopal (masyarakat menyebut kopal dengan nama damar) telah lama dilakukan oleh masyarakat yang berada di sekitar KPHL Kab. Luwu Timur (Model Unit I Larona Malili). Bahkan beberapa masyarakat telah menjadikan kegiatan pemanenan getah damar ini sebagai mata pencaharian pokok dan tenaga 
kerjanya semua berasal dari anggota keluarga. Di beberapa daerah, kegiatan berkebun damar dapat menciptakan sumber pendapatan baru bagi masyarakat, misalnya dengan menjadi buruh saat kegiatan pemanenan, pengangkutan dari kebun ke desa, penyimpanan, sortasi, dan pengangkutan ke para pedagang besar di pasar. Untuk kegiatan pemanenan dan pengangkutan dilakukan oleh pemilik kebun, pengangkutan dan sortasi dilakukan oleh pekerja upahan, sedangkan kegiatan penyimpanan dilakukan oleh pedagang pengumpul. Oleh sebab itu, masyarakat dapat menikmati keuntungan dari budidaya damar ini meskipun tidak memiliki kebun damar sendiri [11]. Sementara di lokasi penelitian, kegiatan yang dilakukan oleh pemilik kebun dan keluarga adalah pemanenan dan pengangkutan getah damar hingga ke rumah mereka, selanjutnya kegiatan pengangkutan dari rumah petani ke pedagang pengumpul dilakukan oleh pedagang pengumpul, namun jika jumlah getah yang akan dijual sedikit ( $\pm 1-2$ karung), maka petani sendiri yang mengantar getah tersebut ke pedagang pengumpul.

Jumlah getah damar yang dihasilkan oleh tiap pohon tidak menentu. Jika produksi damar sedang baik, dalam sekali panen bisa dihasilkan getah damar sebanyak 35-40 kg yang diperoleh dari 10-12 batang pohon damar, namun jika produksi sedang turun hasil tersebut peroleh dari 20 pohon damar. Penurunan produksi tersebut kirakira sebesar 30-40\%. Getah damar akan mengalir melalui kulit pohon damar yang telah dilukai terlebih dahulu sebelumnya. Satu pohon bisa dibuat beberapa buah lubang sadap, biasanya lubang dibuat dengan bentuk segitiga yang disusun secara vertikal maupun horizontal. Jumlah lubang sadap, kedalaman serta ukuran sangat mempengaruhi jumlah produksi yang dihasilkan oleh setiap pohon. Namun jumlah lubang sadap dan kedalaman yang berlebihan tidak akan memberikan hasil yang optimal, justru akan mengganggu pertumbuhan pohon damar tersebut. Oleh sebab itu sangat dibutuhkan adanya pelatihan atau sosialisasi tentang cara pembuatan lubang sadap yang baik agar produktifitas getah juga dapat meningkat.

Menurut [12], beberapa faktor yang mempengaruhi produksi kopal adalah kualitas tempat tumbuh, umur pohon, kerapatan tegakan, sifat genetik, ketinggian tempat tumbuh di atas permukaan laut, ketebalan kulit batang, besarnya diameter batang, topografi, kualitas tajuk dan arah penyadapan. Kondisi tegakan yang terlalu rapat akan menghasilkan tegakan dengan diameter kecil, sehingga dengan diameter pohon yang kecil akan mengakibatkan produksi damar per pohon juga relatif kecil. Akibat tegakan yang terlalu rapat, mengakibatkan cahaya matahari yang masuk juga kurang, sehingga menyebabkan suhu udara di dalam tegakan menjadi rendah. Dengan suhu yang rendah, membuat getah damar menjadi cepat mengeras sehingga penetesan menjadi lambat. Dengan diameter pohon yang kecil juga akan mempengaruhi jumlah lubang sadap, semakin besar diameter maka semakin banyak pula lubang sadap dan semakin banyak pula getah yang dihasilkan. Selain itu, produkstifitas damar juga sangat dipengaruhi oleh ketebalan kulit pohon damar. Damar yang berkulit tebal menghasilkan lebih banyak getah daripada damar yang bekulit tipis.

Hasil penelitian [13] menyatakan bahwa, kulit batang yang tebal dihasilkan oleh diameter pohon yang besar juga, jadi semakin besar diameter pohon semakin tebal kulit batangnya, semakin banyak jaringan ephitel pada kulit batang yang memproduksi kopal. Menurut [14], umumnya damar yang mempunyai kulit tebal juga mempunyai tajuk yang lebih rindang dibandingkan dengan agathis berkulit tipis, sehingga akan menghasilkan getah yang lebih banyak. [12] menyatakan bahwa peningkatan kelerengan juga mempengaruhi produksi getah, semakin tinggi kelerengan tempat tumpuh, produksi kopal juga semakin banyak.

Getah damar dipanen sendiri oleh pemilik kebun bersama dengan keluarganya. Namun jika sang pemilik kebun berhalangan, biasanya menggunakan jasa orang lain untuk melakukan pemanenan getah damar ini. Pekerja ini biasanya berasal dari warga setempat. Pekerja diupah dengan uang. Pemanenan getah damar dilakukan setiap 3 bulan sekali, dan tiap 15 hari dilakukan pelukaan kembali (Pattodongi) agar takik-takik yang telah dilukai bisa mengeluarkan getah lagi sehingga jumlah getah yang diperoleh tiap tiga bulan bisa meningkat daripada jika tidak dilakukan pelukaan kembali.

Saat ini semua biaya berupa peralatan pemanenan tersebut sepenuhnya menjadi tanggungan petani pemungut karena saat ini semua hasil pemanenan masih menjadi hak milik petani penggarap sehingga semua biaya menjadi tanggung jawab mereka. Masyarakat diberi akses untuk dapat mengelola getah damar yang ada sehingga mereka sudah merasa bahwa pohon damar yang mereka olah saat ini adalah milik mereka, namun masyarakat sadar bahwa lahan tempat pohon damar tersebut tumbuh adalah milik negara. Peran penggelola KPH saat ini baru sebatas pengamanan kawasan jika terjadi gangguan atau pencurian kayu di dalam kawasan hutan. 


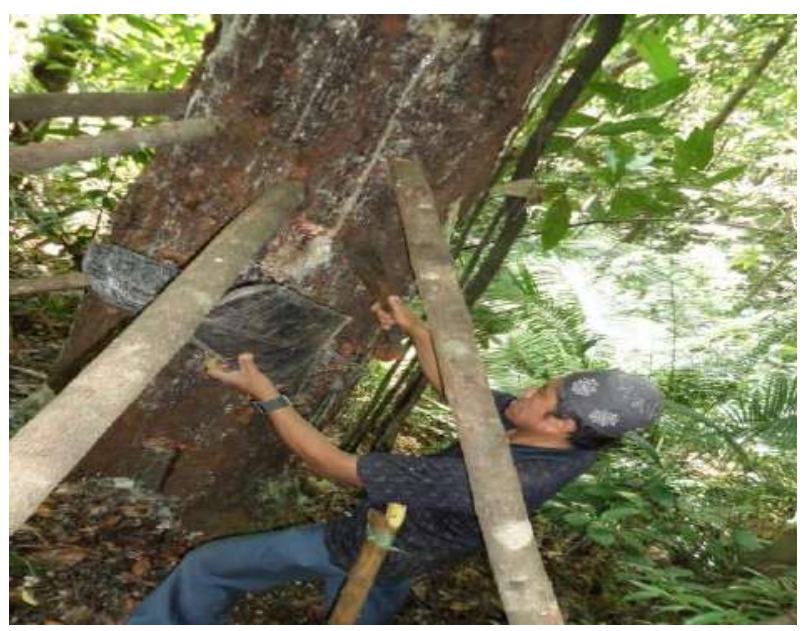

(a) Pembuatan sayatan pada pohon

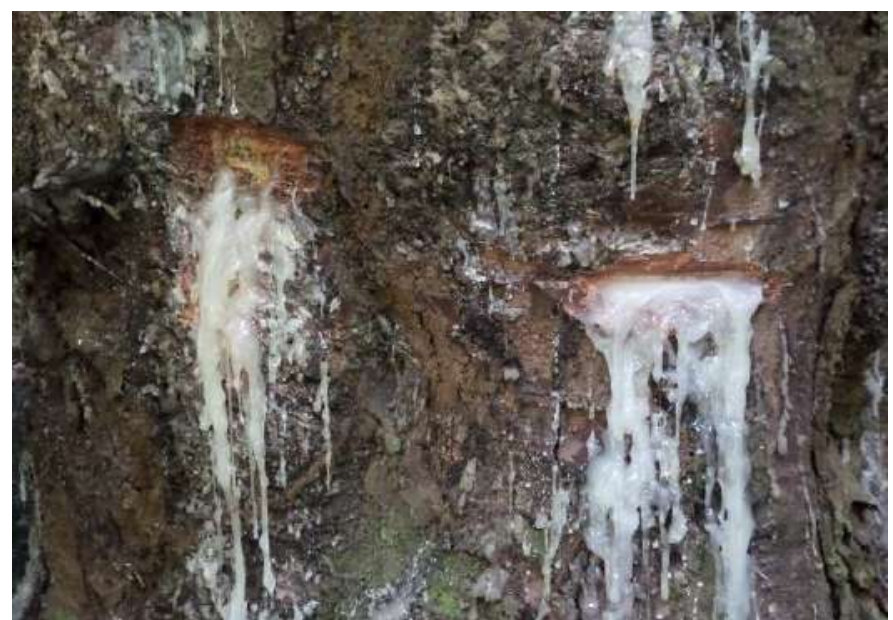

(b) Getah yang keluar setelah batang pohon damar di sayat

Gambar 7. Proses pemanenan getah damar

\subsection{Manfaat Ekonomi Getah Damar Bagi Masyarakat}

Pendapatan getah damar dihitung berdasarkan hasil kali antara produktifitas getah damar/tahun dikalikan dengan harga pasar atau harga jual getah damar yang berlaku saat itu di lokasi penelitian. Tidak ada penggolongan kualitas damar di pembeli atau pedagang pengumpul, sehingga damar dibeli dengan harga yang seragam di semua pengumpul.

Kegiatan pemanenan getah damar di lokasi penelitian dilakukan setiap 3 (tiga) bulan sekali. Adapun kegiatan yang dilakukan sebelum melakukan pemanenan adalah membersihkan pohon damar dari tanaman-tanaman pengganggu yang dikhawatirkan dapat mengganggu produktivitas getah damar. Pohon damar yang terpilih untuk disadap (diameter 20 up) kemudian dilukai kulit batangnya agar getah damar dapat mengalir keluar. Selanjutnya setiap 15 hari sekali, pohon damar dilukai lagi di di tempat luka yang pertama tadi agar getah yang keluar semakin banyak. Setelah 3 (tiga) bulan, getah dipanen dengan menggunakan parang khusus untuk damar (parang palele), penadah (tambu-tambu) dan karung. Pemanenan biasanya dilakukan selama $10-15$ hari, tergantung luas lahan dan jumlah pohon di dalamnya.

Berdasarkan hasil wawancara dengan responden, rata-rata pohon damar yang dimiliki oleh responden adalah 50 pohon/ha dengan rata-rata produksi getah/pohon adalah $2.685 \mathrm{~kg} /$ tahun. Jika harga jual getah damar saat dilakukan penelitian sebesar Rp10.000,00/kg maka rata-rata pendapatan responden dari nilai jual getah damar adalah sebesar Rp26.850.000,00/tahun. Hal ini menunjukkan, adanya pemanfaatan getah damar dapat meningkatkan kesejahteraan masyarakat di sekitar kawasan di KPHL Larona Malili.

\section{Kesimpulan}

Salah satu cara yang dapat dilakukan untuk melindungi hutan dari kerusakan adalah melalui upaya konservasi hutan lindung secara partisipatif yaitu memberikan akses kepada masyarakat untuk mengelola hutan secara bertanggung jawab. Pemanenan getah damar merupakan salah satu pemanfaatan HHBK dari dalam hutan lindung yang dapat dikelola oleh masyarakat. Pohon damar banyak terdapat di dalam kawasan KPHL larona Malili, baik hutan produksi maupun hutan lindung dan tersebar di 5 (lima) Kecamatan yaitu Kecamatan Towuti, Malili, Nuha, Wasuponda dan Angkona. Kegiatan pemanenannya selama ini telah lama dilakukan oleh masyarakat. Bahkan beberapa masyarakat telah menjadikan kegiatan pemanenan getah damar ini sebagai mata pencaharian pokok. Untuk menjaga kualitas getah, maka kegiatan pemanenannya dilakukan 3 bulan sekali. Pemanenan getah damar 
memberikan manfaat ekonomi sebesar Rp26.850.000,00/tahun atau sebesar Rp2.237.500,00/bulan. Dengan demikian diharapkan adanya kesadaran dari masyarakat untuk melakukan budidaya pohon damar secara mandiri demi terjaganya keberlanjutan kegiatan pemanenan getah damar di dalam kawasan KPHL Larona Malili.

\section{Ucapan Terima Kasih}

Terima kasih disampaikan kepada Balai Penelitian dan pengembangan Lingkungan Hidup dan kehutanan Makassar yang telah memberikan dukungan dana sehingga kegiatan penelitian ini dapat terwujud. Ucapan terima kasih juga kami sampaikan kepada Kepala KPHL Larona Malili beserta stafnya yang telah membantu kami selama pengambilan data di lapangan, masyarakat di sekitar KPHL Larona Malili, tokoh masyarakat, dan pihak-pihak yang telah membantu selama kami melaksanakan kegiatan penelitian. Tidak lupa kami ucapkan terima kasih kepada Heru Setiawan, dan Arman Hermawan yang telah membantu dalam kegiatan pengambilan data di lapangan.

\section{Referensi}

[1] Noer, “ Memasyarakatkan Hutan Lindung”. 2011. https://noerdblog.wordpress.com/2011/05/05/memasyarakatkan-hutan-lindung/ diakses pada tanggal 16 Oktober 2018.

[2] Purwanti, R., “Analisis Kelayakan Pembangunan KPHL Kab. Luwu Timur (Model Unit 1 Model Unit 1 Larona Malili)”. Thesis Universitas Gadjah Mada (UGM). Yogyakarta, 2015.

[3] KPHL Larona Malili, "Profil KPHL Larona Malili”. Tidak Diterbitkan. 2012.

[4] Godoy, R., Wilkie, D., Overman, H., Cubas, A., Cubas, G., Demmer, J., et al., "Valuation Of Consumption And Sale Of Forest Goods From A Central American Rain Forest". Ecologycal Economic, 62-63, 2000. Diakses dari http://www.sciencedirect.com.ezproxy.ugm.ac.id pada tanggal 25 Januari 2014.

[5] Sheil dan Wunder, 2002; Sheil, D., Wunder, S., "The Value Of Tropical Forest To Local Communities: Complications, Caveats, And Cautions". Conservation Ecology 6 (2), 9, 2002.Available from: http://www.consecol.org/vol6/iss2/art9. Diakses tanggal 25 Januari 2014.

[6] Kar, S.P., Jacobson, M.G.,. "NTFP income contribution to household economy and related socio-economic factors: Lessons from Bangladesh". Forest Policy and Economics 14 (2012) 136-142, 2011. www.elsevier.com/locate/forpol. Diakses dari http://www.sciencedirect.com.ezproxy.ugm.ac.id pada tanggal 25 Januari 2014.

[7] Angelsen, A., Wunder, S., "Exploring the forest poverty link: key concepts, issues and research implications". CIFOR Occasional Paper No. 40. CIFOR, Bogor, Indonesia, 2003. Diakses dari http://www.cifor.org/publications/pdf_files/occpapers/op-40.pdf pada tanggal 27 Januari 2014.

[8] Neumann, R.P., and Hirsch, E., "Commercialisation Of Non-Timber Forest Products: Review And Analysis Of Research". Center for International Forestry Research, Bogor, Indonesia, 2000. Diakses dari http://www.cifor.org/publications/pdf_files/mgntfp3.pdf. pada tanggal 25 Januari 2014.

[9] Arikunto, S., "Prosedur Penelitian. Suatu Pendekatan Praktik". Rineka Cipta. Jakarta, 2006.

[10] Singarimbun, M. dan Effendi, S., "Metode Penelitian Survai”, Jakarta: LP3ES, 1989.

[11] Michon, G., de Foresta H., Kusworo A. and P. Levang, "Chapter 7. The Damar Agro-Forests of Krui, Indonesia: Justice for Forest Farmers". In C. Zerner (Editor): People, Plants and Justice. Columbia University Press, 2000.

[12] Munajat, I., "Studi Penyusunan Model Penduga Produksi Kopal di Hutan Pendidikan Institut Pertanian Bogor Gunung Walat, Sukabumi, Jawa Barat”. Skripsi. Departemen Manajemen Hutan Fakultas Kehutanan IPB. Bogor, 2004.

[13] Lempang, M., "Uji Beberapa Pola Sadap Untuk Menduga Produksi Kopal Dari Pohon Agathis (Agathis hamii M.Dr.)”. Buletin Penelitian Kehutanan Vol. 2. No. 1. BPK Ujung Pandang., 1997.

[14] Soenarno, M.M. dan Idris, "Copal Production on Agathis spp. Of Varying Bark Thicknesses, Cicurug Sub Forest District, Sukabumi Forest District, West Java”. Duta Rimba. 81-82/XIII. Perum Perhutani Hal. 3-6., 1987. 